\title{
Macroeconomic constraints to growth of Brazilian economy
}

\author{
JOSÉ LUIS OREIRO*
}

In the last 20 years the Brazilian economy averaged an annual growth rate of only $0.7 \%$ in per-capita terms, well below the value of about $3 \%$ it reached between 1950 and 1980. Performance was also below that of similar emerging countries like South Korea, China, Mexico and Chile. If it were to continue at such a speed, Brazil would need about 100 years to double per-capita income, and even so it would never reach anything near the standard of living of the present developed countries.

The main factors for low growth in the last 20 years are well known. We can pinpoint two fundamental disequilibrium in the economy, which in a long run perspective account for its semi-stagnation. On one side, there is a progressively increasing internal disequilibrium, as a result of the attempt to cope with inflation via mechanisms of price and wage indexation, which have contributed to maintain inflation high and with a persistent tendency to accelerate. Only the "Plano Real" managed to curbe down the inflationary tendency, at least partially. At the same time, domestic disequilibrium was reduced by means of a monetary policy that was excessively conservative, to the effect of keeping the country's rates of interest among the highest in the world, at the same time as generating the currency appreciation in the period between 1994 and 1998.

The default on the external debt declared in 1987, exposed the extent and weight of Brazil's external disequilibrium. This latter was the result of a policy that had excessively relied on external savings and the current account as instruments to finance economic growth in the second half of the 1970. The current account deficit, practically eliminated in the second part of the 1980, was to reappear during the first mandate of Fernando Henrique Cardoso, as a result of the adoption of an exchange rate anchor. The correction of such disequilibrium could only be real-

*Professor, Department of Economics, University of Brasilia. E-mail: joreiro@unb.br. 
ized in 1999, with the switch in the exchange rate regime and the subsequent depreciation of the nominal exchange rate.

The last four years have witnessed an acceleration of the growth of the Brazilian economy as compared to the years after 1988. The average growth rate of the period 2004-2007 was around 4,5\%, well above the average performance during any othe previous period: $2000-2003$ (2,35\% p.a.), $1996-1999$ (1,45\% p.a.), 1992-1995 (3,48\%) and 1988-1991 (-0,05\%). Assuming an annual growth of population in the order of $1,5 \%$, that GDP growth rate will imply that income per-capita in Brazil will return to grow at an annual rate of $3 \%$, thus recovering the levels of performance of the 1950-1980 period.

The acceleration of growth was made possible by a combination of two elements: a strong increase in the growth rate of exports since 2000, which proved to be fundamental in accelerating the pace at which aggregate autonomous demand was growing, pushing in this way growth of production, and a relevant increase in the rate of gross fixed capital formation since 2004. This latter contributed significantly to an increase of output, for it allowed the production capacity to adjust to the rate of expansion of aggregate demand.

However, there are sources of fragility that could lead to a sudden and sharp reduction in the expansion of exports and in the growth rate of gross fixed capital accumulation, causing a collapse of the current expansion pattern. Indeed, the growth pace of the Brazilian economy has at least two macroeconomic sources of fragility, one related to the exchange rate and another related to the short-term interest rate. These sources are responsible for the existence of a "high interest rate-low exchange rate trap".

The first source is the remarkable exchange rate misalignment, especially since 2005. In contrast to what was recently put forward by Brazilian economists with an orthodox viewpoint, we think that the real exchange rate appreciation in recent years is not due to a reduction in its equilibrium value, but is related to its overevaluation with respect to such a value.

A second source of fragility, which could have been operating for various years, is related with the inefficacy of monetary policy. Notwithstanding the fall in the rate of interest, Brazil's levels are still among the highest in the world, both in nominal and real terms. High interest rates over a long period of time have been among the results of the low efficacy of monetary policy. It is the consequence of such inefficacy that convergence of the inflation rate to its chosen long term target requires comparatively higher real interest rates. At the root of that inefficacy are the characteristics of the reaction function of the Brazilian Central Bank. In our interpretation of the determination of the basic rate, the Selic, the BCB's policy is driven by an "excessive care" for and over-reacts to inflationary pressures that are generated, fundamentally, by costs hikes due to changes in the nominal exchange rate. Such bias towards overreacting affects sensibly gross fixed capital formation and through it the pace of long run growth.

The high share of controlled prices in the composition of the IPCA and the relevance of the rate of exchange in the determination of the Selic, both directly 
and indirectly through expectations and the IPCA itself, dictate a perverse pace of monetary policy. This happens partly due to certain amplifying effect that high portion of controlled prices has onto interest rates. Actually this fact has as a shortcoming that any exchange rate variation exerts greater effects onto prices and finally the interest rate than otherwise.

The dynamics of the determination of the Selic, as shown by some econometric exercises, indicate that the action of interest rates over the output gap does not comply with the logic of a traditional Phillips curve. In this logic, in fact, a rise in nominal, and real, interest rates would cause a reduction in output levels, thus forcing a reduction in the inflation rate.

As is well known, in the logic of the Phillips curve, changes in the rate of exchange bring about changes in the inflation rate. This is not what the previous econometric exercises show for the Brazilian economy, though. This is due to the fact that the changes in Selic are first of all determined, directly and indirectly, by the behaviour of the exchange rate, as a consequence of the fact that the former, while causing changes in the rate of capacity utilization, has no perceivable effect upon the exchange rate or the inflation rate. Put differently, the changes in exchange rate values do cause changes in the rate of inflation and the interest rates, so that monetary policy ends up having to react to a cost inflation pressure, but has no little or no effect as a measure to control the Brazilian inflation.

Therefore, although monetary policy only plays a passive role, reacting to inflation rate, at the end the degree of such causality is very modest. As a consequence, rises in the Selic rate only show that they are having less and less efficacy. This apparent anomaly can be imputed to the high share of controlled prices which are indexed by IGP-M, an index that, by construction, follow the behaviour of nominal exchange rate - in the IPCA as these do not respond to Selic, as well as to the perverse behaviour of the public debt market in Brazil. This latter characteristic is connected with the low wealth effect of monetary policy, which is due to the excessive share of indexed bonds, the so-called Letras Financeiras do Tesouro, in the composition of the Brazilian Federal Domestic Debt. These bonds are indexed to the basic interest rate - the Selic- which means that their Duration in Macauley sense is zero. Since duration is zero, these bonds have zero interest rate risk, which greatly reduces the wealth effect of monetary policy. Due to a low wealth effect, the impact of interest rate variations over aggregate demand is reduced, forcing monetary authorities to produce great increases in the basic rate in order to produce the contraction of aggregate demand that they think is required for the achievement of the target level for inflation. But this huge increase in the basic rate of interest is responsible for the exchange rate appreciation which has the effect of reducing inflationary pressures, on one hand, but reduces the competitiveness of exports, causing a slowdown in economic growth, in other hand.

Although monetary authorities in Brazil intervene in exchange rate market, exchange rate regime in Brazil can be considered a (dirty) floating since there is no commitment of Central Bank with a pre determined exchange rate level. Since the majority of capital controls were removed in Brazil in the beginning of the 1990s, 
we can suppose that a situation of near perfect capital mobility prevails in Brazilian economy. This means that the short term dynamics of nominal exchange rate can be explained by means of the uncovered interest rate parity as show by equation (1).

$$
i=i^{*}+\left(E^{e} / E\right)-1
$$

Where: $\mathrm{i}$ is the domestic short term interest rate, $\mathrm{i} *$ is the foreign short-term interest rate, $\mathrm{E}$ is the actual level of nominal exchange rate and $\mathrm{E}^{\mathrm{e}}$ is the expected level of nominal exchange rate in the future.

From the estimation of reaction function of the Central Bank we can say that short-term nominal interest rate is determined by:

$$
i=f(E, \ldots .), f^{\prime}>0(2)
$$

Combining equations (1) and (2) we can determine shot term interest rate and nominal exchange rate, as shown by Figure 1 .

\section{Figure 1}

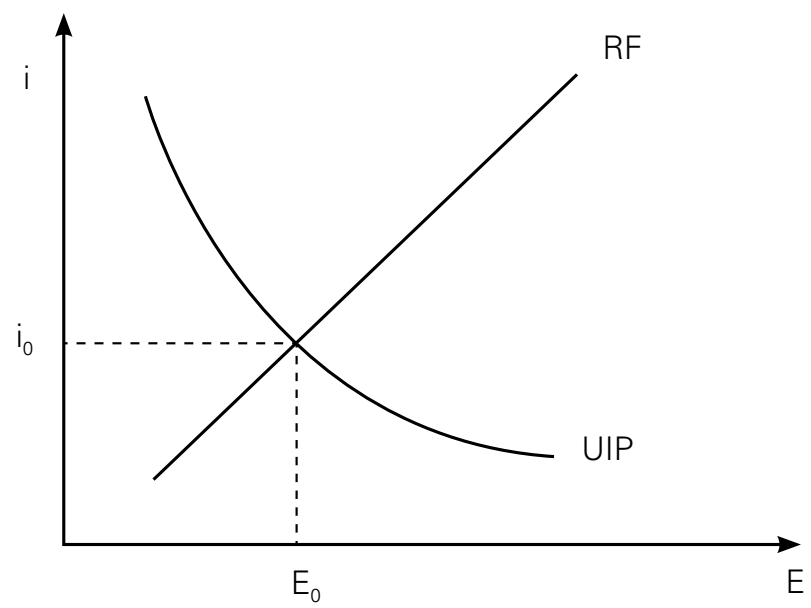

Where: UIP is the "uncovered interest rate parity" and RF is the "reaction function" of the Central Bank.

Consider now an exogenous increase in price level of commodities - for example, caused by speculation in commodity markets. This will be equivalent to a negative supply shock, causing an immediate increase in domestic rate of inflation. According to our econometric model, monetary authorities in Brazil will react to such an event by means of an increase in the short-term interest rate, displacing the $\mathrm{RF}$ curve to the left (Figure 2). As a consequence of interest rate increase, nominal exchange rate will fall (appreciation), increasing the over-valuation of real exchange rate. 


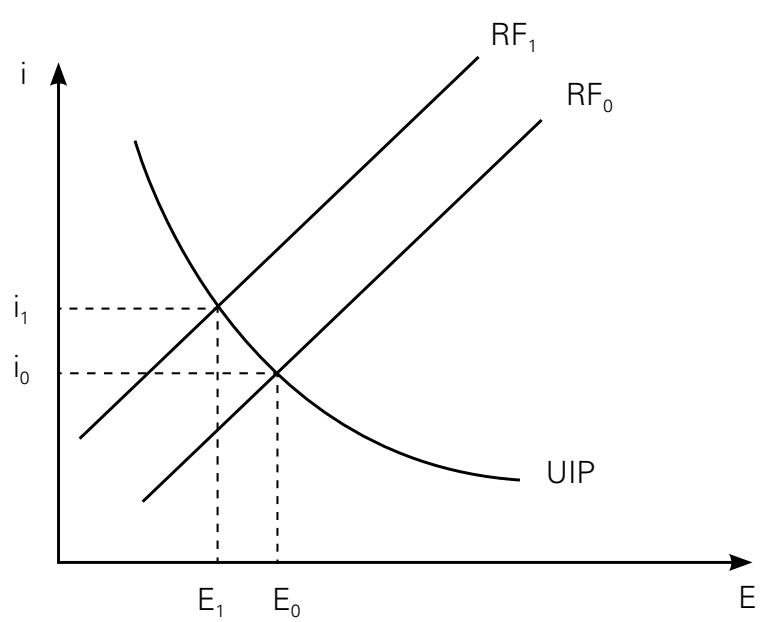

From Figure 2 we can see that the combination of a (dirty) floating exchange rate system with a rigid inflation targeting regime can produce a perverse combination of high short-term interest rate and over-valued exchange rate in face of negative supply shocks. The elimination of the "high interest rate-low exchange rate trap" is a necessary condition for the relaxation of macroeconomic constraints to long-term growth of Brazilian economy. In the next section we will present some policy proposals to solve this macroeconomic problem.

The elimination of the macroeconomic constraints to the output growth needs to be pursued along two directions: exchange rate policy and monetary policy. More explicitly, the government has to pursue the promotion of a controlled depreciation of nominal exchange rate, while at the same time it has to alter fundamentally the modus operandi of the monetary policy, allowing for a temporary rise in the inflation rate. This latter is necessary to make possible an adjustment in the real exchange rate, without initializing a process of rising interest rates.

A managed exchange rate depreciation has to be realized through purchases of international reserves by the Central Bank. Such operations have to aim not just at an increase in the international reserves, but at the gradual elimination of the exchange misalignment. In other words, the Central Bank has to operate having implicit targets as to the nominal rate of exchange.

To reach such targets without restricting the BCB freedom to fix the basic rate of interest, it will be necessary to introduce a system of control over the outflow of short term capital. In fact, from the moment economic agents will perceive that the monetary authority is pursuing an implicit exchange rate target, implying a gradual depreciation of exchange rate, there will be a capital flight from the country. This outflow will be further reinforced by the reduction in domestic interest rates, following the change in the approach to monetary policy.

Recalling the international experience of capital controls, in particular on the basis of the lessons learned during the exchange rate crisis of Malaysia (1997-1998), controls on outflows will have to be of an administrative and all encom- 
passing character, so as to be bypassed. A temporary prohibition to capital exit is not to be discarded as a measure in the initial phase of implementation of this new macroeconomic policy model.

The implementation of a regime of implicit exchange rate targets requires large scale sterilization operations. Their costs will be lower the lower the basic interest rate. In this way, the change in the modus operandi of monetary policy becomes necessary not only to prevent the interest rate hike that would follow the elimination of the exchange misalignment, but also to reduce the fiscal costs of the exchange policy.

On the other hand, the switch in monetary policy has to go together with the substitution of actual inflation targeting regime (ITR, hereafter) for a "double mandate regime" (DMR, hereafter) where Brazilian monetary authorities must pursue two objectives of monetary policy; that is: output stabilization and inflation control. Although advocates of ITR stress that both functions can be performed by this framework of monetary policy (see Bernanke et al., 1999), we do not share this optimistic view for a variety of reasons. First of all, ITR is based on New Consensus on Macroeconomics (Arestis and Sawyer, 2006a, 2006b) that considers output to be supply constrained in the long-run.

There are a lot of empirical evidences showing that growth is demand-led in Brazilian economy. Second, ITR take for granted that inflation acceleration is always and elsewhere the result of a situation of excess demand. But this is certainly not the case for Brazilian economy, where inflation responds strongly to variations in nominal exchange rate rather than to variations in capacity utilization. To stabilize inflation in Brazil it is necessary to reduce the level of price indexation to exchange rates, what can be done by a simple change of contracts of public services, forcing controlled prices to be indexed by IPCA (General Consumer Price Index) rather than by IGP-M (General Level of Market Prices), which is an index that, by construction, follow the behaviour of nominal exchange rate. As a complementary device for inflation control it is necessary for Brazilian Treasury to get rid off indexed public bonds, the so-called Letras Financeiras do Tesouro, that are also responsible for a low effect of interest rate changes over aggregate demand.

However, to make the exchange rate adjustment viable, inflation will have to be temporarily increased to an interval between 5 and $8 \%$ annual rate. From the evidence available, we can deduce that these rates of inflation are not prejudicial to economic growth in emerging economies.

\section{REFERENCES}

ARESTIS, P., SAWYER, M. (2006a). "The nature and role of monetary policy when money is endogenous”, Cambridge Journal of Economics, 30, 847-860.

ARESTIS, P., SAWYER, M. (2006b). "Interest rates and the real economy", in: C. Gnos, L.P. Rochon (eds.). Post Keynesian Principles of Economic Policy, Aldershot, Edward Elgar

BERNANKE, B. S., LAUBACH, T., MISHKIN, F.S., and POSEN, A. S. (1999). Inflation Targeting: Lessons from the International Experience. Princeton: Princeton University Press. 